Supporting information of

\title{
Copper-Gallic acid nanoscale metal-organic framework for combined drug delivery and photodynamic therapy
}

Shalini Sharmał, Disha Mittalll, Anita Kamra Vermall and Indrajit Roy*ł

‡ Department of Chemistry, University of Delhi, Delhi-110007

||Department of Zoology, Kirori Mal College, University of Delhi-110007

*Email: indrajitroy11@gmail.com

Table of Contents

1. Characterization

1.1. FTIR

1.2. BET measurement

2. Optical Studies

2.1. UV-Vis Spectra and Fluorescence Spectra

2.2. $\mathrm{H}_{2} \mathrm{O}_{2}$ measurement

3. In vitro

3.1. Cytotoxicity in presence of anti-oxidant GSH

4. In vivo

4.1. Tumour weight data 


\section{Characterization}

\subsection{FTIR}

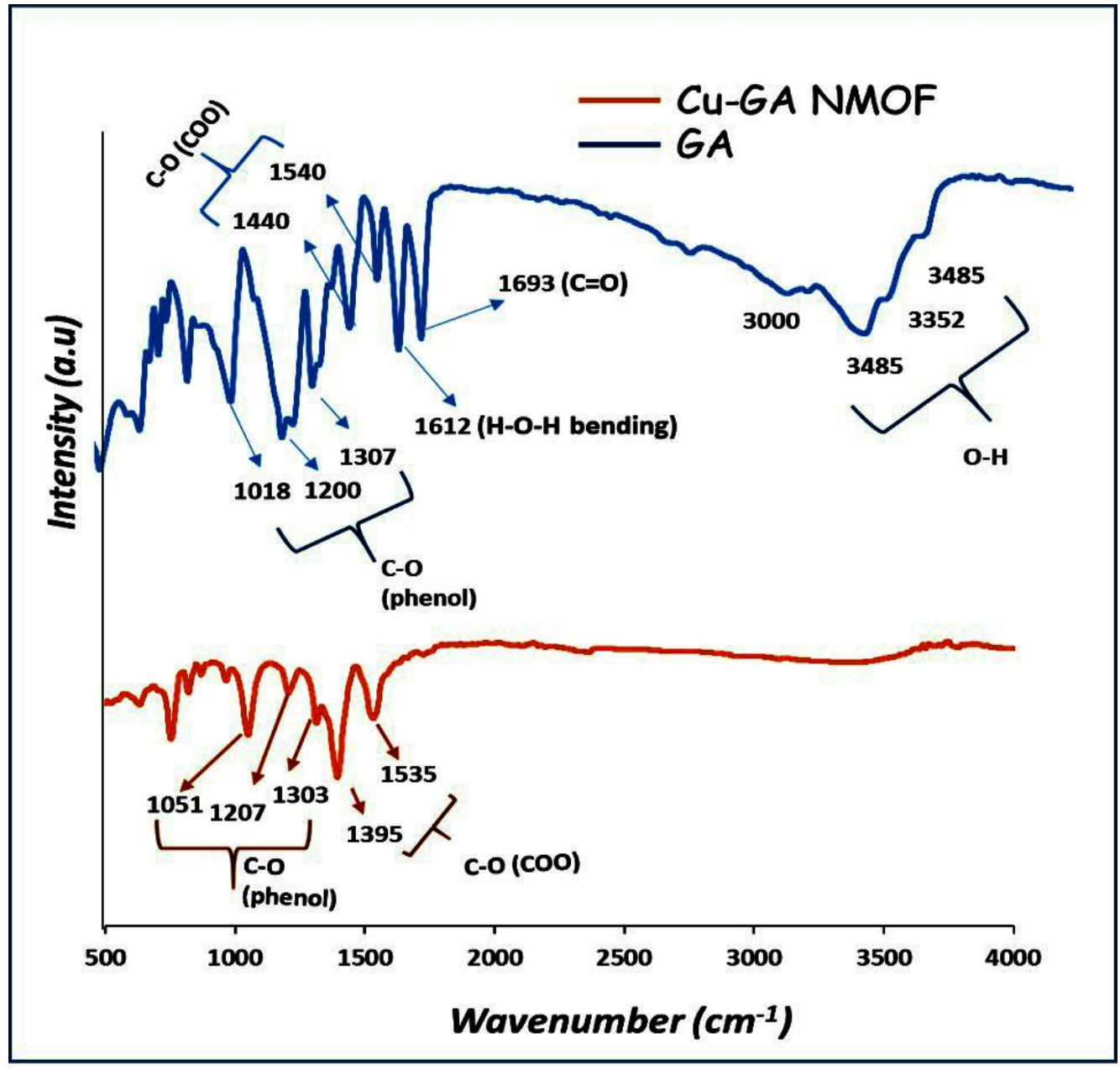

Figure S1: Fourier transform infrared (FTIR) spectra of free GA and Cu-GA NMOF 


\subsection{BET mesurement}

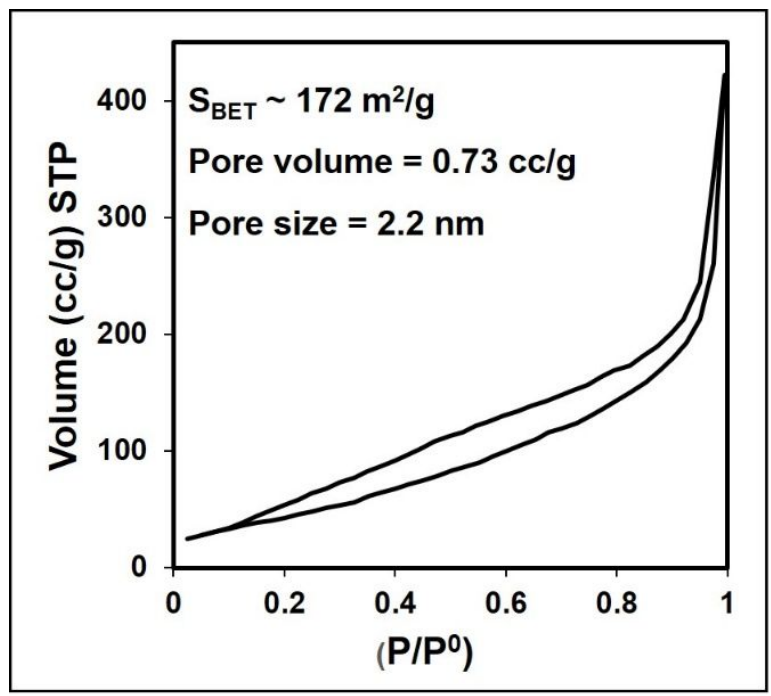

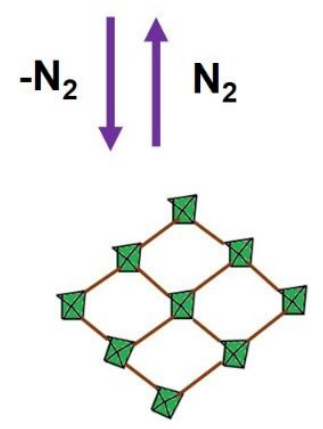

Narrow Pores

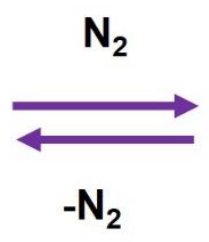

Large Pores

Figure S2: Nitrogen adsorption and desorption isotherm of Cu-GA NMOF with its breathing behaviour. 


\section{Optical Studies}

\section{1. $\mathrm{H}_{2} \mathrm{O}_{2}$ Measurement}

In this assay, various dosages of GA from free and its equivalent concentration within $\mathrm{Cu}-\mathrm{GA}$ NMOF was mixed with $1 \mathrm{ml}$ of PBS (pH=7.4) containing $160 \mu \mathrm{L}$ of HRP $(25 \mathrm{U} / \mathrm{ml})$ and 100 $\mu \mathrm{L}$ of o-dianisidine dye $(10 \mathrm{mg} / \mathrm{ml}$ in methanol) and incubated for $40 \mathrm{~min}$ at $\mathrm{RT}$. The reaction was stopped by addition of $10 \mu \mathrm{l}$ of $2 \mathrm{M} \mathrm{HCl}$. Here, the concentration range $(0-100 \mu \mathrm{g} / \mathrm{ml})$ used for free GA and its equivalent concentration within $\mathrm{Cu}-\mathrm{GA}$ NMOF for $\mathrm{H}_{2} \mathrm{O}_{2}$ determination. After incubation, the samples were centrifuged and the collected supernatant was used for recording the absorbance at $430 \mathrm{~nm}$. The concentration of $\mathrm{H}_{2} \mathrm{O}_{2}$ was determined by using the molar extinction coefficient of oxidized o-dianisidine $\left(11.3 \mathrm{Lmol}^{-1} \mathrm{~cm}^{-1}\right)$.

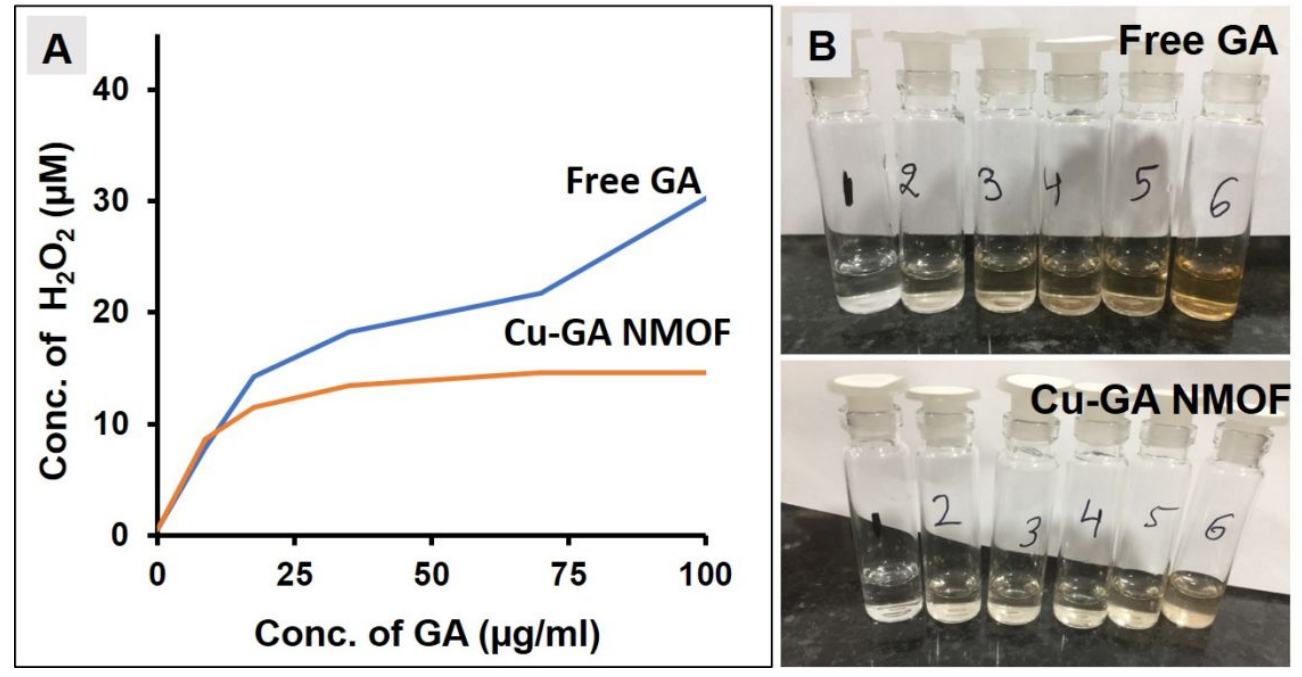

Figure S3: (A) Comparative estimation of $\mathrm{H}_{2} \mathrm{O}_{2}$ from free GA and its equivalent concentration within Cu-GA nano-framework; (B) Image showing colour change of o-dianisidine detector with increasing concentration of generated $\mathrm{H}_{2} \mathrm{O}_{2}$ obtained from free GA and Cu-GA NMOF (various concentrations of GA are labelled as: $1=0 \mu \mathrm{g} / \mathrm{ml}, 2=10 \mu \mathrm{g} / \mathrm{ml}, 3=20 \mu \mathrm{g} / \mathrm{ml}, 4=40$ $\mu \mathrm{g} / \mathrm{ml}, 5=70 \mu \mathrm{g} / \mathrm{ml}$, and $6=100 \mu \mathrm{g} / \mathrm{ml}$ ). 

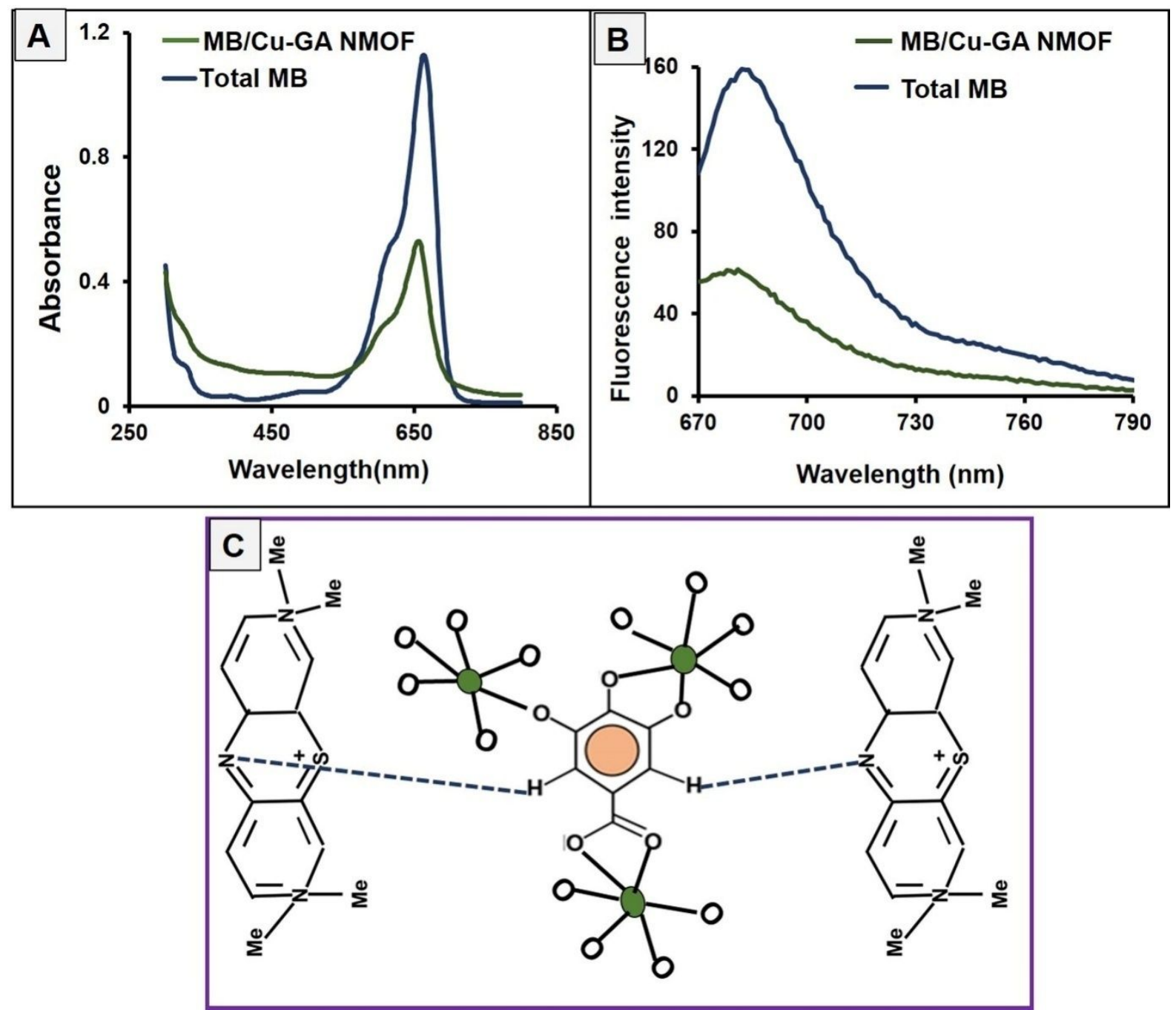

Figure S4: Optical properties of MB loaded Cu-GA NMOF; (A) and (B) represents Absorption spectra $\left(\lambda_{\mathrm{ex}}=650 \mathrm{~nm}\right)$ and Fluorescence spectra $\left(\lambda_{\mathrm{em}}=680 \mathrm{~nm}\right)$ of total MB and MB/Cu-GA NMOF. (C) Schematic showing the H-bonding interaction between gallic acid (center) and methylene blue (on both sides). 


\section{In vitro studies}

3.1. Cytotoxicity in the presence of anti-oxidant GSH. The auto-oxidation of GA produces ROS which has been confirmed by using anti-oxidant glutathione (GSH) as ROS quencher. In this MTT assay, we pre-treated the cells with $20 \mathrm{mM}$ aqueous solution of GSH for 2 hours, followed by the treatment of free GA and $\mathrm{Cu}-\mathrm{GA}$ NMOF (at their $\mathrm{IC}_{50}$ ) dosage for 24 hours. The usual procedure of MTT assay was followed in the paper.

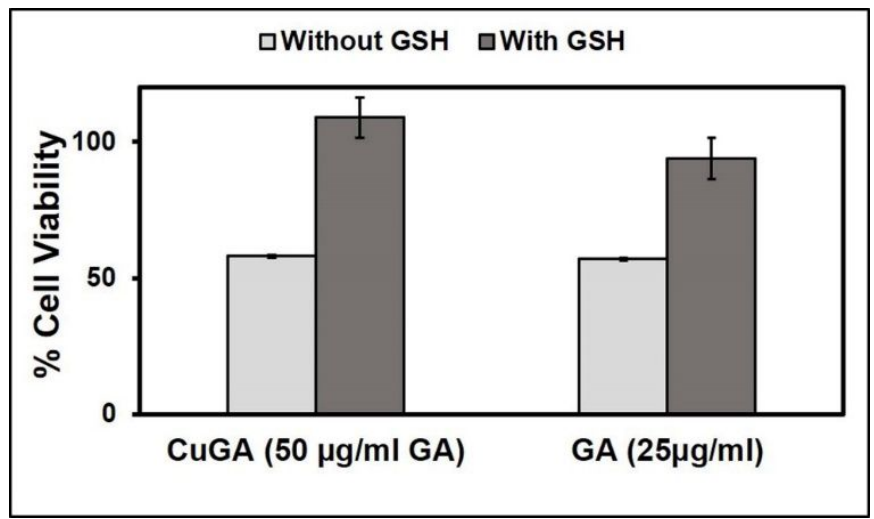

Figure S5: Cell viability assay (MTT) showing the protection of cells from ROS mediated cytotoxicity by free GA and Cu-GA NMOF using anti-oxidant (GSH)

\section{In vivo studies}

Introduction of EAC tumors in Mice. Ascites developed within 7-10 days after the inoculation of EAC cells in mice. The ascitic fluid was obtained under aseptic conditions from these mice and washed twice with normal saline by centrifugation at 10,000 rpm. After washing, the EAC cells were tested for viability using trypan blue, examined microscopically using a haemocytometer, counted and resuspended in normal saline containing $2 \times 10^{6}$ cells/ $/ 1 \mathrm{ml} .100 \mu \mathrm{l}$ of ascites was injected subcutaneously in freshly shaved mice for developing solid tumours on the dorsal side. Measurable tumour appeared 7 days post 
inoculums. Palpable tumours were measured in two perpendicular diameters using the Vernier Caliper and tumour volume was calculated by the formula:

$$
\mathrm{V}=\mathrm{LW}^{2} / 2
$$

Where, $\mathrm{V}=$ Tumour Volume, $\mathrm{L}=$ Tumour dimension at the longest point, and $\mathrm{W}=$ Tumour dimension at the widest point.

Animal maintenance. The in vivo studies were conducted on Balb/c mice of female sex, aged 5-6 weeks, weighing 20-25 g, and housed in polycarbonate cages (five mice per cage) at an ambient temperature of $25 \pm 2{ }^{\circ} \mathrm{C}$ and relative humidity $(55+5 \%)$ with a 12-hour light/dark cycle. The mice were fed with commercially obtained rodent chow (Golden feed, Delhi, India) and water ad libitum

Statistical analysis: The results were expressed as Mean standard deviation. Comparison among groups were analysed by One-way ANOVA and means were separated by Tukey's test using Prism (5.0) software (Prism software Inc. CA). Levels of significance were accepted at $\leq 0.05$ level.

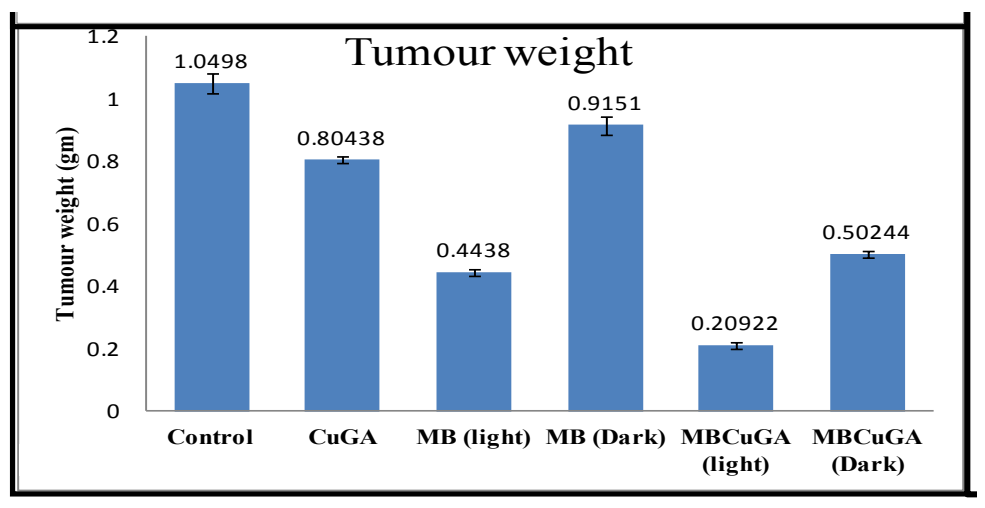

Figure S6: Weight of the tumours obtained on the Day of Sacrifice indicating that for mice treated with $\mathrm{MB} / \mathrm{Cu}-\mathrm{GA}$ and laser, tumour has regressed the most when compared to other groups. 


\begin{tabular}{|c|c|c|c|c|c|c|c|c|c|c|c|}
\hline Group & Day 1 & & Day3 & Day5 & Day 7 & Day 10 & Day 12 & Day 14 & Day 18 & Day 20 & $\begin{array}{l}\text { Day } 21 \\
\text { (Sacrifice) }\end{array}$ \\
\hline Control & & 0 & $39.41 \pm 4.1$ & $63.12 \pm 3.8$ & $87.73 \pm 3.6$ & $121.88 \pm 9.9$ & $165.79 \pm 8.5$ & $180.52 \pm 10.0$ & $222.00 \pm 13.5$ & $245.99 \pm 8.2$ & $311.29 \pm 12.5$ \\
\hline CuGA & & 0 & $32.90 \pm 3.8$ & $59.85 \pm 4.7$ & $87.16 \pm 1.7$ & $112.34 \pm 10.0$ & $131.86 \pm 4.9$ & $143.93 \pm 17.0$ & $159.16 \pm 22.2$ & $181.06 \pm 12.8$ & $199.95 \pm 8.1$ \\
\hline MB(light) & & 0 & $42.63 \pm 3.0$ & $69.37 \pm 2.4$ & $89.17 \pm 2.7$ & $123.32 \pm 11.3$ & $134.84 \pm 13.3$ & $144.28 \pm 11.2$ & $159.31 \pm 12.4$ & $163.92 \pm 13.1$ & $177.59 \pm 8.2$ \\
\hline MB(Dark) & & 0 & $38.44 \pm 1.2$ & $65.20 \pm 2.1$ & $95.85 \pm 3.5$ & $155.11 \pm 13.0$ & $152.06 \pm 7.1$ & $168.13 \pm 17.2$ & $182.14 \pm 15.1$ & $197.76 \pm 17.4$ & $219.74 \pm 9.9$ \\
\hline MBCuGA (light) & & 0 & $44.23 \pm 4.8$ & $72.59 \pm 2.3$ & $91.87 \pm 4.6$ & $76.59 \pm 9.5$ & $56.51 \pm 10.9$ & $48.39 \pm 11.7$ & $30.63 \pm 9.8$ & $26.00 \pm 10.0$ & $22.57 \pm 7.1$ \\
\hline MBCuGA (Dark) & & 0 & $34.49 \pm 4.2$ & $68.00 \pm 2.7$ & $94.35 \pm 4.2$ & $115.25 \pm 8.0$ & $135.19 \pm 4.5$ & $152.48 \pm 3.5$ & $158.80 \pm 6.4$ & $180.46 \pm 8.1$ & $183.55 \pm 10.3$ \\
\hline
\end{tabular}

Table S1: Tumour volumes on respective days in different groups 